\title{
First report on extended distance between tumor lesion and adjacent organs at risk using interventionally applied balloon catheters: a simple procedure to optimize clinical target volume covering effective isodose in interstitial high-dose-rate brachytherapy of liver malignomas
}

\author{
Peter Hass, MD',2, Ingo G. Steffen, MD³, Maciej Powerski, MD²,4, Konrad Mohnike, MD², , Max Seidensticker MD²,6, \\ Frank Meyer, MD7, Thomas Brunner, MD', Robert Damm, MD4, Christoph Willich, MDl, Mathias Walke, PhD!, \\ Efstratios Karagiannis, MD , Jazan Omari, MD4, Jens Ricke, MD²,6 \\ 'Department of Radiation Oncology, University Hospital, Magdeburg, Germany, ${ }^{2}$ International School of Image-Guided Interventions, \\ Magdeburg, Germany, ${ }^{3}$ Department of Nuclear Medicine, University Medical Center Charité, Berlin, Germany, ${ }^{4}$ Department of Radiology \\ and Nuclear Medicine, University Hospital, Magdeburg, Germany, ${ }^{5}$ DTZ am Frankfurter Tor, Center for Radiology, Berlin, Germany, \\ ${ }^{6}$ Department of Clinical Radiology, Ludwig-Maximilians-University (LMU), Munich, Germany, ${ }^{2}$ Department of General, Abdominal, Vascular, \\ and Transplant Surgery, University Hospital, Magdeburg, Germany, ${ }^{8}$ Department of Radiation Oncology, German Oncology Center, \\ Limassol, Cyprus
}

\begin{abstract}
Purpose: Organs at risk (OARs), which are very close to a clinical target volume (CTV), can compromise effective tumor irradiation. The present study investigated the feasibility and safety of a novel approach, in particular, the extent of the dosimetric effect of distancing CTV from adjacent OARs by means of interventionally applied balloon catheters.

Material and methods: Patients with peripheral hepatic malignancies, in whom the critical proximity of an OAR to the CTV in the assessment by contrast-enhanced magnetic resonance imaging (MRI) scans and the preplanning process were included. Additionally, patients underwent placement of an interventional balloon catheter during computed tomography (CT)-guided application of interstitial brachytherapy (iBT) catheters inserted into the tissue between hepatic capsule and adjacent OAR. The virtual position of an OAR without balloon catheter was anticipated and contoured in addition to contouring of CTV and OAR. The calculated dose values for CTV as well as $1 \mathrm{cc}$ of the relevant OAR $\left(\mathrm{D}_{1 \mathrm{cc}}\right)$ with and without balloon were recorded. The $\mathrm{D}_{1 \mathrm{cc}}$ of the realized irradiation plan was statistically compared to the $\mathrm{D}_{1 \mathrm{cc}}$ of the virtually contoured OARs.

Results: In 31 cases, at least one balloon catheter was administered. The mean $\mathrm{D}_{1 \mathrm{cc}}$ of the OAR in the group with balloon(s) was 12.6 Gy compared with 16 Gy in the virtual cohort without the device, therefore significantly lower $(p<0.001)$. Overall, there were no acute complications. Severe (> 2 CTCAEv4.03) late complications observed in 3/31 $(9.6 \%)$ patients during follow-up period after brachytherapy were most certainly not due to the balloon application. Side effects were probably associated with pre-existing serious diseases and potentially additional local late effects of the irradiation in general rather than with the balloon catheters.

Conclusions: The distancing of the adjacent OARs allows a higher $\mathrm{D}_{100}$ value of CTV, therefore allowing for more efficient local control.

Key words: balloon catheters, clinical target volume (CTV), dose per $1 \mathrm{cc}\left(\mathrm{D}_{1 \mathrm{cc}}\right)$, dose volume histogram (DVH), interstitial high-dose-rate (HDR) brachytherapy (iBT), liver malignancies, organ at risk (OAR).

Address for correspondence: Peter Hass, MD, Department of Radiation Oncology, University Hospital at Magdeburg, Leipziger Strasse 44, 39120 Magdeburg, Germany, phone: +49 391 6715795, fax: +49 391 6715324,® e-mail: peter.hass@med.ovgu.de
Received: 05.09 .2018

Accepted: 01.04 .2019

Published: 29.04.2019 


\section{Purpose}

The concept of oligo-metastasis [1] based on surgical studies $[2,3,4]$ that was discussed for the first time in the 1990s, differs from the rigid scheme of palliation vs. curation. There is a cohort of oligo-metastasized patients, which is not yet clearly definable that benefits from a consequent local ablation in terms of an improvement in the overall prognosis [5]. The gold standard of local treatment is surgical procedure [6]. However, since a high proportion of hepatic oligo-metastases is not resectable, alternative ablation procedures have been successfully tested [7]. The "toolbox of ablative treatments" is now a part of the current "ESMO (European Society for Medical Oncology) guidelines for the management of patients with metastatic colorectal cancer" [8].

In this study, radio-ablative methods are particularly investigated.

The development of high-performance software for calculation and application of prescribed irradiation dose and device-based hardware, currently allow for very precise implementation of hypo-fractionated and radio-surgical approaches $[9,10]$. Therefore, in no resectable patient, primary and secondary liver malignancies can often be treated very effectively with radiotherapy [11]. The key for effective and sustainable radio-ablation is to provide adequate clinical target volume doses [12,13], taking into account the dose limits of adjacent organs at risk (OARs). Particularly, in the case of marginal liver tumor, compromises cannot often be avoided at the expense of a potentially reduced chance of local control.

The aim of the present analysis was to investigate the feasibility and safety of a novel approach, in particular, to examine whether an increase in the distance between the target volume and the structure at risk is technically possible without severe complications and to what extent a dosimetric advantage is generated.

\section{Material and methods}

\section{Patients}

As a rule, all patients who might be eligible for brachytherapy of the liver are considered by a tumor board prior to the initial presentation at our department. A standard operating procedure (SOP) defines the inclusion and exclusion criteria for performing interstitial brachytherapy (iBT) of the liver. All patients sign a written informed consent prior to planning a computed tomography (CT)- or magnet resonance imaging (MRI)-guided interstitial brachytherapy. From April 2009 to June 2016, 2,082 patients with primary or secondary liver tumors were treated with interstitial high-dose-rate (HDR) brachytherapy; 137 cases $(6.6 \%)$ had subcapsular liver tumors near the stomach, duodenum, or large intestine (OAR).

From this cohort, 31 patients were included in the study and received one or two additional balloon catheter(s) to increase the distance between the hepatic margin/surface and adjacent OAR, as part of single stage CT-guided iBT (recorded dose-volume histogram (DVH) parameters, Table 1 and Figure 1).
The prescribed dose related to $D_{100}$ depends on the histology of the primary tumor lesion (GIST [gastrointestinal stromal tumor] $=12 \mathrm{~Gy}$, breast cancer, renal cell carcinoma, hepatocellular carcinoma $=15 \mathrm{~Gy}$, other histologies $=20$ Gy). The dose was applied as a single fraction targeted on the complete tumor ablation.

\section{Method}

Methodology and course of single-dose interstitial HDR brachytherapy was already described in detail elsewhere [12,14].

Briefly, HDR-brachytherapy catheters (Primed, Halberstadt, Germany) and angiographic occlusion balloon catheters (Equalizer ${ }^{\mathrm{TM}}$ Occlusion Balloon Catheter, 20 and $27 \mathrm{~mm}$, Boston Scientific, Marlborough, USA) were placed in a similar way using CT fluoroscopy (Aquilion Prime, Canon Medical Systems, Neuss, Germany). Following the puncture of the target lesion (for brachytherapy catheters) or between the liver capsule with the adjacent target lesion and the OAR (for balloon catheters) with an 18-G coaxial needle, a stiff angiography wire (Amplatz Super Stiff ${ }^{\mathrm{TM}}$, Boston Scientific, Boston, MA, USA) was introduced for placement of a $6 \mathrm{~F}$ (for brachytherapy catheters) or $12 \mathrm{~F}$ (for balloon catheters) introducer sheath (Radifocus ${ }^{\circledR}$, Terumo, Tokyo, Japan), using the Seldinger technique, through which the brachytherapy or balloon catheter was inserted. When in the correct position, the balloon catheter was inflated (with contrast medium) to dissociate the OAR from the target volume (Figure 2). After placement of brachytherapy and balloon catheters, a contrast agent-enhanced (intravenously, iodine-based, $80 \mathrm{ml}$ ) spiral CT in breath-holding-technique (slice thickness, $3 \mathrm{~mm}$ ) of the liver was acquired. The catheter position, the tumor margin, and anatomic risk structures verified by contrast-enhanced images were sent to the treatment planning unit (Oncentra Brachy, Elekta AB, Stockholm, Sweden).

The decision to insert a balloon catheter was made after the evaluation of liver specific MRI scans (slice thickness, $3 \mathrm{~mm}$; MRI protocol included: T2-weighted ultra-turbo spin echo sequences with and without fat saturation, diffusion-weighted imaging, a T1-weighted gradient echo sequence, T1-weighted dynamic sequences, and sequences acquired $20 \mathrm{~min}$ after IV administration of 0.1 $\mathrm{ml} / \mathrm{kg}$ Gd-EOB-DTPA [Primovist ${ }^{\circledR}$, Bayer Vital, Leverkusen, Germany] performed on an 1.5-tesla MRI scanner [Intera 1.5T, Philips Healthcare, Hamburg, Germany], if within the framework of a virtual catheter application, the calculated clinical target volume (CTV) enclosing prescription dose $\left(D_{100}\right)$ did not seem to be feasible under consideration of the institutional OAR dose limits concerning $\mathrm{D}_{1 \mathrm{cc}}$ and $\mathrm{V}_{5}[13,15,16]$, and outstanding publications and reviews, inter alia, by Timmermann, Herfarth et al. and Sterzing et al. $[17,18,19]$ (Table 2).

The time for insertion of one balloon catheter corresponds approximately to the application time of two BT catheters (mean, $16 \mathrm{~min}$ ). In case of an implant with one BT catheter tripling the intervention time and in case of more advanced liver lesions with 8 catheters, the duration time of the intervention increases by approximately $25 \%$. 
Table 1. Recorded dose-volume histogram (DVH) parameters

\begin{tabular}{|c|c|c|c|c|c|}
\hline $\begin{array}{l}\text { Patient } \\
\text { study } \\
\text { number }\end{array}$ & $\begin{array}{l}\text { Prescribed sin- } \\
\text { gle-dose for } \mathrm{D}_{100} \\
\text { CTV (Gy) }\end{array}$ & $\begin{array}{l}\text { Calculated dose } \\
\text { for } \mathrm{D}_{100} \text { CTV with } \\
\text { balloon }(\mathrm{Gy})\end{array}$ & Adjacent OAR & $\begin{array}{l}\text { Accepted calculated } \\
\text { dose for OAR } D 1_{c c} \\
\text { with balloon }(G y)\end{array}$ & $\begin{array}{c}\text { Calculated dose for } \\
\text { anticipated OAR } \\
\text { without balloon }\end{array}$ \\
\hline 1 & 20 & 10.560 & Stomach & 15.720 & 16.195 \\
\hline 2 & 12 & 6.700 & Stomach & 13.500 & 21.798 \\
\hline 3 & 15 & 7.740 & Duodenum & 12.250 & 12.420 \\
\hline 4 & 20 & 8.750 & Stomach & 14.250 & 15.610 \\
\hline 5 & 20 & 9.330 & Stomach & 13.938 & 16.501 \\
\hline 6 & 15 & 15.117 & Large intestine & 16.540 & 25.130 \\
\hline 7 & 20 & 11.010 & Stomach & 13.880 & 14.440 \\
\hline 8 & 15 & 14.250 & Stomach & 12.980 & 15.460 \\
\hline 9 & 20 & 20.300 & Stomach & 9.320 & 13.924 \\
\hline 10 & 15 & 12.050 & Stomach & 14.010 & 15.456 \\
\hline 11 & 20 & 20.580 & Duodenum & 13.510 & 16.160 \\
\hline 12 & 20 & 20.930 & Stomach & 14.220 & 15.625 \\
\hline 13 & 20 & 20.670 & Stomach & 11.390 & 14.310 \\
\hline 14 & 20 & 20.830 & Stomach & 13.560 & 14.290 \\
\hline 15 & 20 & 15.886 & Stomach & 14.350 & 15.964 \\
\hline 16 & 15 & 15.130 & Stomach & 8.970 & 21.030 \\
\hline 17 & 12 & 12.310 & Stomach & 11.290 & 13.390 \\
\hline 18 & 15 & 15.240 & Stomach & 14.280 & 23.787 \\
\hline 19 & 15 & 13.140 & Stomach & 11.160 & 13.910 \\
\hline 20 & 20 & 20.827 & Stomach & 9.200 & 11.130 \\
\hline 21 & 20 & 15.440 & Stomach & 12.310 & 14.700 \\
\hline 22 & 15 & 9.940 & Stomach & 13.685 & 14.957 \\
\hline 23 & 15 & 15.146 & Stomach & 10.230 & 13.389 \\
\hline 24 & 25 & 27.420 & Stomach & 9.920 & 16.870 \\
\hline 25 & 25 & 25.300 & Stomach & 13.430 & 17.220 \\
\hline 26 & 20 & 15.150 & Stomach & 14.810 & 14.920 \\
\hline 27 & 25 & 25.290 & Stomach & 13.640 & 17.688 \\
\hline 28 & 20 & 20.700 & Stomach & 12.220 & 15.497 \\
\hline 29 & 25 & 27.560 & Stomach & 8.890 & 18.160 \\
\hline 30 & 15 & 13.900 & Stomach & 10.437 & 11.300 \\
\hline 31 & 20 & 22.530 & Stomach & 13.710 & 15.459 \\
\hline
\end{tabular}

Prescribed and calculated dose for $D_{100}-C T V$, accepted calculated dose for OAR-D $D_{1 c c}$ with balloon, calculated dose for OAR-D $D_{1 c c}$ regarding anticipated OAR-contour without balloon.

In addition to CTV, liver and adjacent OAR (predominantly stomach) as well as virtual OAR volume without a balloon were contoured; the virtual position of the OAR could be anticipated by assessing the pre-interventional MRI scans and additionally, with the interventional CT scans with BT catheter only (Figure 1).

Dose calculation was performed in strict accordance with institutional OAR limits (Table 2). The relevant parameters for this analysis such as prescription dose, $\mathrm{D}_{100}-\mathrm{CTV}, \mathrm{D}_{1 \mathrm{cc}}-\mathrm{OAR}$ with and without a balloon were re- corded. The values for the $\mathrm{D} 1_{\mathrm{cc}} \mathrm{OAR}$ with and $\mathrm{D} 1_{\mathrm{cc}} \mathrm{OAR}$ without balloon were distinguished as two groups and statistically evaluated.

The values for $\mathrm{D} 1_{\mathrm{cc}}-\mathrm{OAR}$ with and $\mathrm{D} 1_{\mathrm{cc}}-\mathrm{OAR}$ without balloon were assigned to two groups. These two cohorts were compared statistically.

Interstitial HDR brachytherapy was performed using an ${ }^{192}$ Ir source with an afterloading device from Elekta (MicroSelectron HDR V3, Oncentra Brachy, Elekta AB, Stockholm, Sweden). 

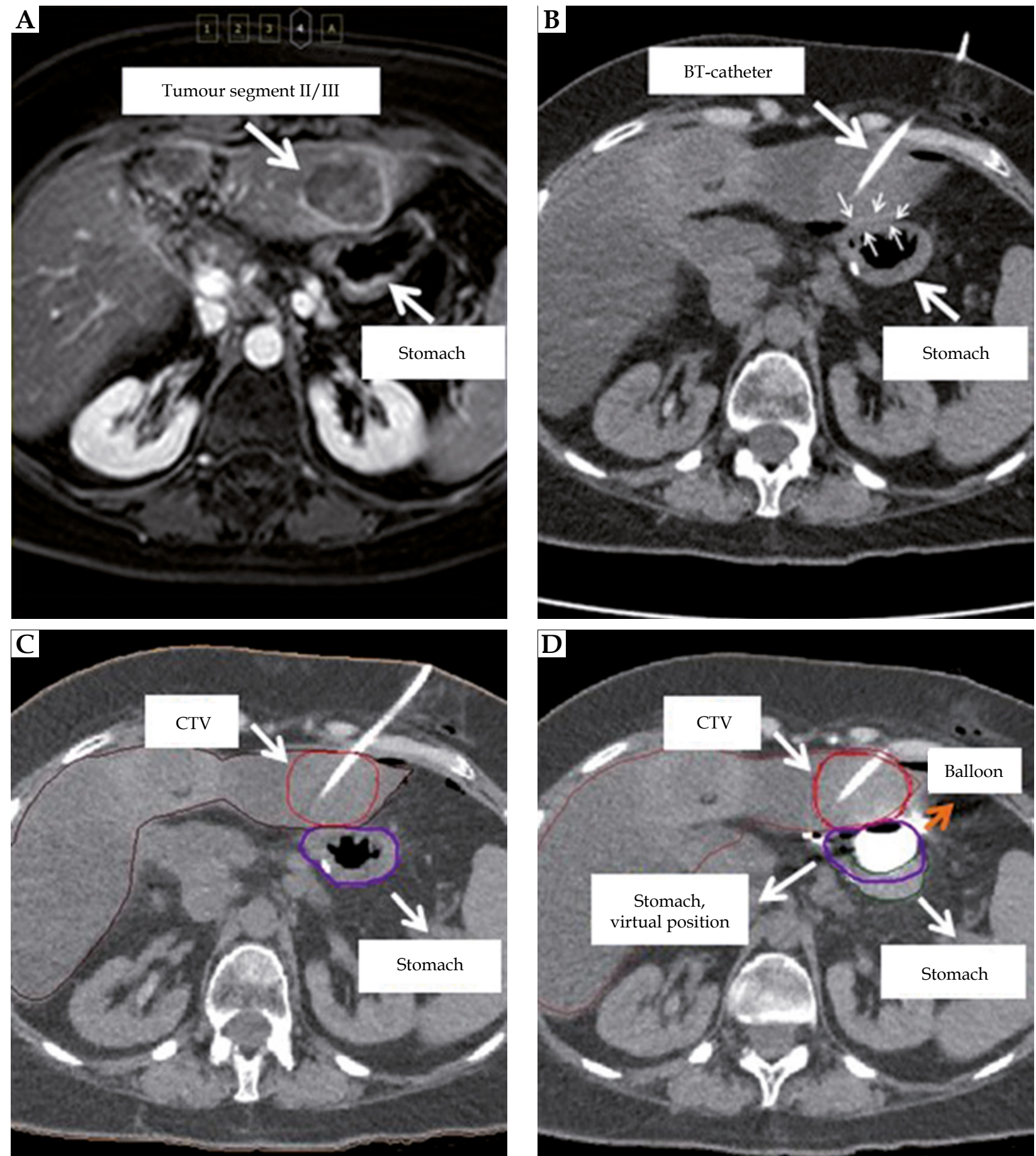

Fig. 1. Tomography imaging: A) Transversal MRI-scan: tumor lesion with marginal enhancement of contrast media, no BT, catheter; distinctly adjacent stomach; B) Corresponding transversal CT-scan with stomach position without balloon; one BT, catheter inserted; C) Corresponding transversal CT-scan; CTV and stomach contoured; D) Corresponding transversal CT-scan with additional balloon; CTV, stomach and stomach, virtual position without balloon contoured

\section{Statistics}

Statistics were collected with R (version 3.1.3; the R Foundation for Statistical Computing, Vienna, Austria).

Due to small sample size, non-parametric distribution of data was assumed, and data were described by median, interquartile range (IQR, $25^{\text {th }}-75^{\text {th }}$ percentiles), and minimum and maximum. Boxplots were used for visu- alization of data. Correlation of data was analyzed with Spearman's rho rank correlation coefficient and agreement of methods was described using Bland-Altman analysis [20]. Paired groups (with/without balloon) were compared with Wilcoxon signed rank test, and optimal cut-off was determined using receiver operating characteristics (ROC) curves [21] and Youden index as appro- 

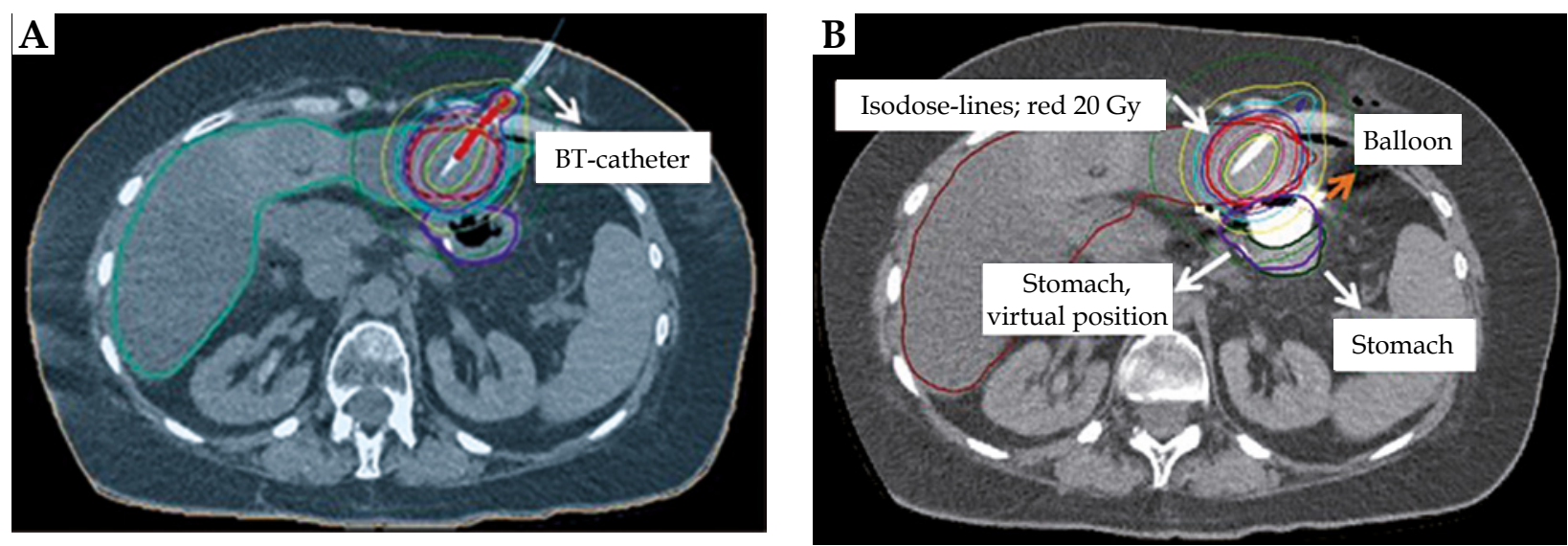

\begin{tabular}{lcccc} 
Resulting D1 $1_{\text {cc }}$ & Dose (\%) & Dose (Gy) & Volume (\%) & Volume (ccm) \\
\hline Stomach without balloon & 113.09 & 22.6184 & 0.10 & 0.10 \\
\hline Liver without balloon & - & - & 0.01 & 0.10 \\
\hline Stomach with balloon & 89.84 & 17.9685 & 0.10 & 0.10 \\
\hline Liver with balloon & - & - & 0.01 & 0.10 \\
\hline Stomach without balloon & 86.23 & 17.2459 & 0.97 & 1.00 \\
\hline Liver without balloon & - & - & 0.06 & 1.00 \\
\hline Stomach with balloon & 69.65 & 13.9301 & 1.01 & 1.00 \\
\hline Liver with balloon & - & - & 0.06 & 1.00
\end{tabular}

Fig. 2. Planning transversal CT scan with isodoses, prescribed dose to $D_{100}$ CTV 20 Gy: A) CT-scan without balloon, one BT-catheter inserted; B) CT-scan with BT-catheter and one balloon-catheter inserted

priate. All tests were two-sided, and the significance level was set as 0.05 .

\section{Statement}

The study was performed according to the guidelines of the Declaration of Helsinki for Biomedical Research from 1964 and its further amendments, and the procedures of "Good Research Practice". The analysis was designed as a retrospective study with approval of the local ethics committee. Each patient signed a written consent form prior to the planned intervention after an adequate patient-physician talk on the intervention and the frequency, severity, and profile of its complications.

\section{Results}

\section{Patients}

Thirty-one patients (17 females, 14 males; median age, 65.3 [range, 38-85] years), $22 \%$ of those with subcapsular liver tumors, were enrolled in the study. In 25 cases, one in 6 cases, two balloon catheters were inserted.

In $74 \%$ of the patients, primary lesions outside the liver were histologically confirmed (colorectal carcinoma, $45 \%$; others, $29 \%$ ), $26 \%$ had primary liver malignancies.

The marginal hepatic lesions were located within the liver segments $2 / 3$ in 29 cases (93.5\%), 2 patients had lesions within the right hepatic lobe, near large

Table 2. Dose constraints regarding organs at risk for single dose

\begin{tabular}{lcccccc} 
Organ at risk & \multicolumn{2}{c}{$\begin{array}{c}\text { Timmermann } \\
\text { SBRT constraints [17] }\end{array}$} & $\begin{array}{c}\text { Herfarth, Sterzing, } \\
\text { SBRT constraints [18,19] }\end{array}$ & $\begin{array}{c}\text { Institutional constraints due to } \\
\text { prospective and retrospective } \\
\text { analysis of the XX/YY } \\
\text { study-group [13,15,16] }\end{array}$ \\
\cline { 2 - 7 } & DVH-parameter & Limit (Gy) & DVH parameter & Limit (Gy) & DVH parameter & Limit (Gy)/(\%) \\
\hline Stomach & $D_{10 c c}$ & $<13.0$ & $D_{\max }$ & 12.0 & $D_{1 c c}$ & $14\left(15^{*}\right)$ \\
\hline Duodenum & $D_{5 c c}$ & $<8.8$ & $D_{\max }$ & 12.0 & $D_{1 c c}$ & $14\left(15^{*}\right)$ \\
\hline Colon & $D_{20 c c}$ & $<11.0$ & Not specified & Not specified & $D_{1 c c}$ & 18 \\
\hline Liver & $D_{700 c c}$ & 9.1 & $D_{50}$ & $4.0-7.0$ & $V_{5}$ & 166
\end{tabular}

*The original values based on Streitparth's work [13] were decreased to 14 Gy from 2012 to further reduce the risk of late toxicity. 
Table 3. Patients' characteristics

\begin{tabular}{|c|c|c|c|c|c|c|}
\hline $\begin{array}{l}\text { Patient } \\
\text { study } \\
\text { number }\end{array}$ & $\begin{array}{l}\text { Age }(y r) \text { at time } \\
\text { of treatment }\end{array}$ & Gender & OAR & $\begin{array}{l}\text { Primary tumor } \\
\text { diagnosis }\end{array}$ & $\begin{array}{l}\text { CTV volume } \\
\quad(\mathrm{ccm})\end{array}$ & $\begin{array}{c}\text { Number }(n) \\
\text { of balloon cath- } \\
\text { eters }\end{array}$ \\
\hline 1 & 78 & Male & Stomach & Colorectal cancer & 23.75 & 1 \\
\hline 2 & 68 & Male & Stomach & $\begin{array}{l}\text { Gastrointestinal } \\
\text { stromal tumor }\end{array}$ & 3.34 & 1 \\
\hline 3 & 44 & Female & Duodenum & Leiomyosarcoma & 3.74 & 1 \\
\hline 4 & 67 & Male & Stomach & Colorectal cancer & 191.7 & 2 \\
\hline 5 & 57 & Female & Stomach & Colorectal cancer & 143.3 & 1 \\
\hline 6 & 63 & Male & Large intestine & Renal cell cancer & 22.3 & 1 \\
\hline 7 & 54 & Female & Stomach & Colorectal cancer & 87.95 & 2 \\
\hline 8 & 64 & Female & Stomach & $\begin{array}{l}\text { Cholangiocellular } \\
\text { carcinoma }\end{array}$ & 336.0 & 2 \\
\hline 9 & 69 & Male & Stomach & $\begin{array}{l}\text { Cholangiocellular } \\
\text { carcinoma }\end{array}$ & 10.3 & 1 \\
\hline 10 & 77 & Male & Stomach & $\begin{array}{l}\text { Hepatocellular } \\
\text { cancer }\end{array}$ & 10.36 & 1 \\
\hline 11 & 70 & Male & Duodenum & $\begin{array}{l}\text { Cholangiocellular } \\
\text { carcinoma }\end{array}$ & 62.7 & 1 \\
\hline 12 & 74 & Female & Stomach & Colorectal cancer & 40.68 & 2 \\
\hline 13 & 69 & Female & Stomach & Colorectal cancer & 18.75 & 1 \\
\hline 14 & 48 & Female & Stomach & Pancreatic cancer & 31.48 & 1 \\
\hline 15 & 56 & Female & Stomach & Colorectal cancer & 134.0 & 2 \\
\hline 16 & 38 & Female & Stomach & Breast cancer & 3.54 & 1 \\
\hline 17 & 73 & Male & Stomach & $\begin{array}{l}\text { Gastrointestinal } \\
\text { stromal tumor }\end{array}$ & 32.35 & 1 \\
\hline 18 & 74 & Male & Stomach & $\begin{array}{l}\text { Cancer of un- } \\
\text { known primary }\end{array}$ & 9.37 & 1 \\
\hline 19 & 46 & Female & Stomach & Breast cancer & 43.76 & 1 \\
\hline 20 & 71 & Female & Stomach & Colorectal cancer & 28.81 & 1 \\
\hline 21 & 75 & Female & Stomach & Colorectal cancer & 101.6 & 1 \\
\hline 22 & 80 & Male & Stomach & Colorectal cancer & 135.2 & 1 \\
\hline 23 & 84 & Female & Stomach & $\begin{array}{l}\text { Hepatocellular } \\
\text { cancer }\end{array}$ & 1.7 & 1 \\
\hline 24 & 56 & Female & Stomach & $\begin{array}{l}\text { Cholangiocellular } \\
\text { carcinoma }\end{array}$ & 2.96 & 1 \\
\hline 25 & 60 & Male & Stomach & Colorectal Cancer & 50.54 & 1 \\
\hline 26 & 85 & Male & Stomach & Colorectal Cancer & 74.0 & 1 \\
\hline 27 & 47 & Male & Stomach & Colorectal cancer & 9.3 & 1 \\
\hline 28 & 74 & Female & Stomach & $\begin{array}{l}\text { Gallbladder } \\
\text { cancer }\end{array}$ & 3.1 & 1 \\
\hline 29 & 70 & Female & Stomach & $\begin{array}{l}\text { Cancer of un- } \\
\text { known primary }\end{array}$ & 35.53 & 2 \\
\hline 30 & 62 & Male & Stomach & $\begin{array}{l}\text { Hepatocellular } \\
\text { cancer }\end{array}$ & 12.3 & 1 \\
\hline 31 & 71 & Female & Stomach & Colorectal cancer & 35.42 & 1 \\
\hline
\end{tabular}

intestine. Patients' characteristics are presented in Table 3.

Application time for the whole implant depended on the number of inserted BT catheters and additional balloons. Median application time was $12.5 \mathrm{~min}$ (range, 7.5-30 min).
Organs at risk (stomach/duodenum, large intestine) $D_{1 c c}$

$\mathrm{D}_{1 \mathrm{cc}}$ of the OAR with balloon (mean, $12 \mathrm{~Gy}$; deviation, 8.9 to $16.5 \mathrm{~Gy}$; median, $13.5 \mathrm{~Gy}$; IQR, 11.2 to $14.0 \mathrm{~Gy}$ ) were significantly $(p<0.001)$ lower compared to virtual antic- 
A

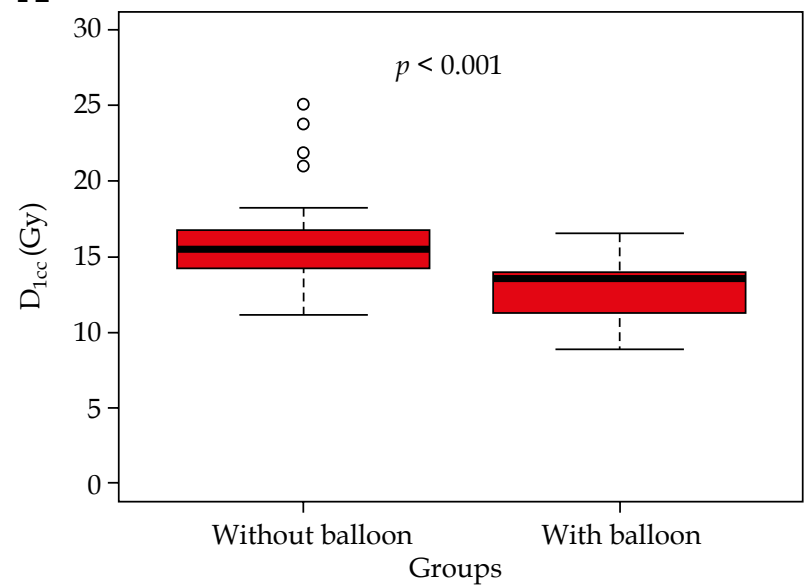

C

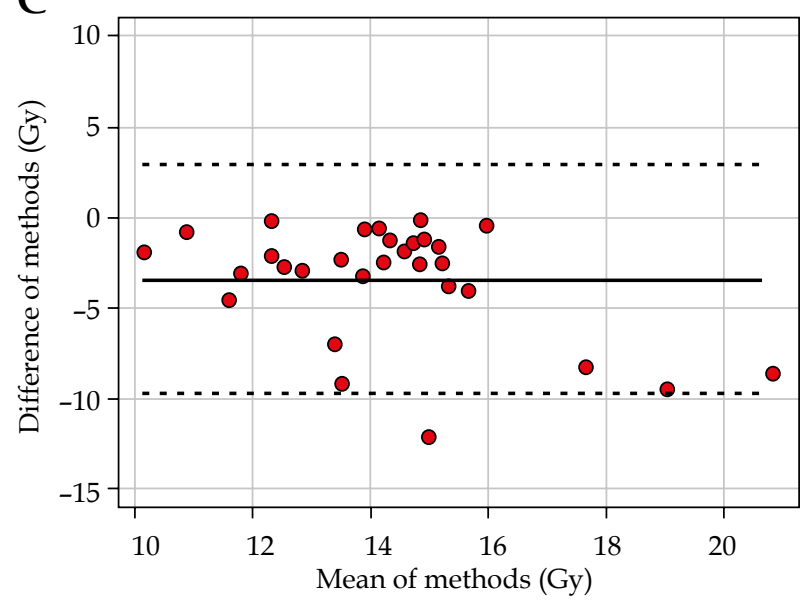

ipated OAR without a balloon (mean, $16 \mathrm{~Gy}$; deviation, 11.1 to $25.1 \mathrm{~Gy}$; median, $15.5 \mathrm{~Gy}$; IQR, 14.3 to $16.7 \mathrm{~Gy}$; Figure $3 \mathrm{~A})$. The corresponding median relative difference was $-16.3 \%$ (IQR, -23.2 to $-8.9 \%$ ), ranging from $-57.3 \%$ to $-0.7 \%$ (Table 4). Figures $3 \mathrm{~A}$ and $3 \mathrm{~B}$ shows the correlation of $\mathrm{D}_{1 \mathrm{cc}}$ with and without a balloon, with a Spearman's correlation coefficient of $0.36(p=0.049)$. Comparing both methods with Bland-Altman, analysis revealed 95\% limits of agreement of $-9.6 \mathrm{~Gy}$ to $2.9 \mathrm{~Gy}$, with a mean of -3.4 Gy (Figure 3C).

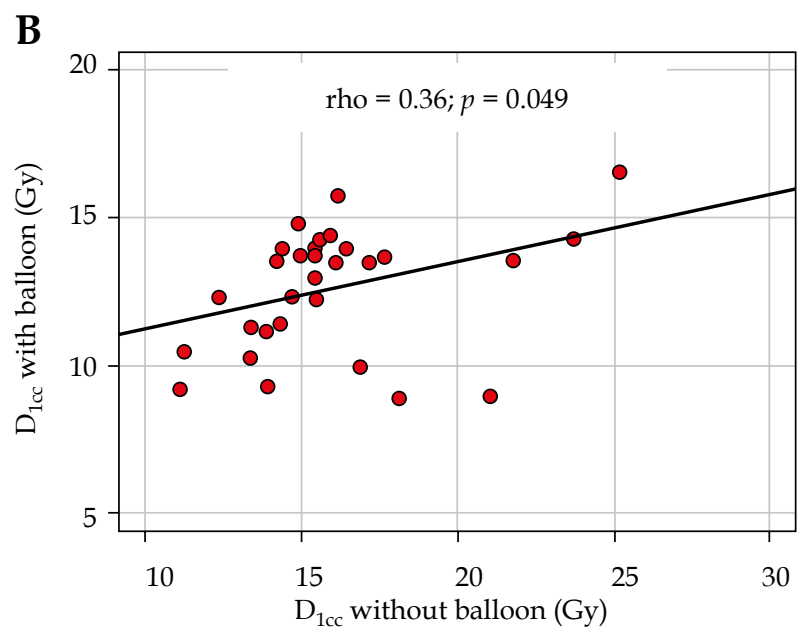

Fig. 3. Boxplots (A), correlation (B), and Bland-Altmanplot $(\mathrm{C})$ of $\mathrm{D}_{1 \mathrm{cc}}$ with and without a balloon

\section{Acute side effects and late morbidity}

The additional balloon catheter was tolerated very well by all patients. Serious acute complications (e.g., bleeding) did not occur in any case. During the further course, 4 late complications in 3 patients $(1 \times$ abscess, $2 \times$ gastric ulcers, $1 \times$ non-classic radiation-induced liver disease [RILD]) were observed. Complications are described in detail in Table 5.

Thus, formally the rate of significant late effects was $12.9 \%(>2)$ and $6.45 \%(>3)$, respectively. Of these, only

Table 4. Statistics: organ at risk $(O A R) D_{1 c c}$ with and without a balloon as well as absolute and relative differences

\begin{tabular}{|c|c|c|c|c|}
\hline Parameter & $\begin{array}{c}\text { OAR without balloon } \\
D_{1 c c}(G y) \\
\end{array}$ & $\begin{array}{l}\text { OAR with balloon } \mathrm{D}_{1 \mathrm{cc}} \\
(\mathrm{Gy})\end{array}$ & $\begin{array}{c}\text { Difference absolute } \\
\text { (Gy) }\end{array}$ & Difference relative (\%) \\
\hline Mean & 16.0 & 12.6 & -3.4 & -19.4 \\
\hline SD & 3.2 & 2.0 & 3.1 & 14.5 \\
\hline Median & 15.5 & 13.5 & -2.5 & -16.3 \\
\hline $25^{\text {th }}$ percentile & 14.3 & 11.2 & -3.9 & -23.2 \\
\hline $75^{\text {th }}$ percentile & 16.7 & 14.0 & -1.4 & -8.9 \\
\hline Minimum & 11.1 & 8.9 & -12.1 & -57.3 \\
\hline Maximum & 25.1 & 16.5 & -0.1 & -0.7 \\
\hline
\end{tabular}


Table 5. Side effects

\begin{tabular}{|c|c|c|c|c|}
\hline $\begin{array}{l}\text { Acute and late side effects accord- } \\
\text { ing to CTCAE }{ }^{\#} \text { v. } 4.03 \text { [1-5] }\end{array}$ & $\begin{array}{l}\text { Number of cases } \\
(n / \%)\end{array}$ & $\begin{array}{l}\text { Patient study } \\
\text { number }\end{array}$ & Treatment/outcome & $\begin{array}{l}\text { Interval between iBT } \\
\text { and side effect }\end{array}$ \\
\hline Temporarily increase of bilirubin $\left[{ }^{\circ} 1\right]$ & $1 / 3$ & 7 & $\begin{array}{l}\text { No treatment/re- } \\
\text { solved }\end{array}$ & $24 \mathrm{~h}$ \\
\hline Shivering $\left[{ }^{\circ} 1\right]$ & $1 / 3$ & 15 & $\begin{array}{l}\text { No treatment/re- } \\
\text { solved }\end{array}$ & $1 \mathrm{~h}$ \\
\hline Nausea/vomiting [ $\left.{ }^{\circ} 2\right]$ & $2 / 6$ & 29 & $\begin{array}{l}\text { Antiemetic drugs/ } \\
\text { resolved }\end{array}$ & $1 \mathrm{~h}$ \\
\hline Abscess [ $\left.{ }^{\circ} 3\right]$ & $1 / 3$ & 20 & $\begin{array}{l}\text { Drainage and antibi- } \\
\text { otics/resolved }\end{array}$ & 8 weeks \\
\hline $\begin{array}{l}\text { Non classic RILD \#\# } \\
\text { (previous } \operatorname{SIRT}^{\star} \text { ) [³] }\end{array}$ & $1 / 3$ & 7 & $\begin{array}{l}\text { Ursodeoxycholic } \\
\text { acid/resolved }\end{array}$ & $\begin{array}{c}12 \text { weeks } \\
\text { (18 weeks after } \\
\text { radioembolization) }\end{array}$ \\
\hline Ulcus ventriculi ${ }^{* \star}\left[{ }^{\circ} 4\right]$ & $1 / 3$ & 20 & $\begin{array}{l}\text { Gastrectomy/re- } \\
\text { solved }\end{array}$ & 14 weeks \\
\hline 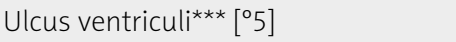 & $1 / 3$ & 11 & Gastrectomy/death & 15 weeks \\
\hline
\end{tabular}

" common terminology criteria for adverse events, \#\#radiation-induced liver disease (RILD), *selective interne radiotherapy (SIRT), ** patient with significantly increased cumulative exposition of gastric mucosa, ${ }^{* * *}$ patient with pre-existing chronic gastritis, long-term avastin-based and/or anticoagulation treatment, severe diabetes mellitus

in one case $(3.22 \%$, patient no. 20$)$ a severe adverse event (SAE) can be suspected due to repeated radiation exposure of the gastric mucosa. Patient no. 11 suffered from diabetes mellitus and pre-existing chronic gastritis, and received long-term treatment with Avastin ${ }^{\circledR}$ (Bevacizumab, Roche Pharma AG, Grenzach-Wyhlen, Germany) and anticoagulation, whereas patient no. 7 underwent a radio-embolization 18 weeks prior to RILD.

\section{Discussion}

The data of this study demonstrate that the interventional application of one or two balloon catheter(s) into the connective tissue layer between the hepatic capsule and adjacent OAR generates a distance between subcapsular tumor lesion of the liver and OAR, resulting in a significant median reduction of dosage exposition of the adjacent OAR of about $16 \%$. This effect enlarges the therapeutic "window" and consecutively, the CTV can be treated with a higher, thus presumably more efficient irradiation dose.

The current ESMO guideline for the treatment of metastatic colorectal cancer (CRC) [8] indicates the growing acceptance of minimally invasive methods for the treatment of oligo-metastases. The so-called "toolbox of minimally invasive methods" is particularly important because a significant proportion of patients with oligo-metastases are not resectable for various reasons [22]. However, in addition to the indisputable role of systemic treatment [23], local control is the key to potentially sustained improvement in the overall prognosis.

Modern irradiation techniques (e.g., stereotactic body radiotherapy [SBRT], iBT) enable precise application of very high single doses. In this regard, in addition to the tumor cell destruction mechanisms based on DNA damage, further effective radiobiological effects can be initiated $[24,25]$. Though, even the most accurate dose application can be limited by the proximity of sensitive OAR.
Chang et al. [26] reported a rate of $\geq 3$ toxicity of $10 \%$ (mainly gastrointestinal [GI] ulceration) after 25 Gy single fraction SBRT for unresectable pancreatic adenocarcinoma, within adjacent stomach and further GI structures.

The concept of simultaneously integrated protection (SIP) could be a conceivable strategy to avoid high doses to an OAR [27]. Whether this is associated with an increased rate of local recurrences is yet to be seen. This question is currently being examined by a prospective clinical study. Therefore, the possibility of increasing distance of the CTV to surrounding OAR appears promising.

In recent years, various groups $[28,29,30]$ have tested feasibility, safety, and application effect of absorbable polyethylene glycol (PEG) to increase the distance between the prostate and the rectal wall. In fact, by applying PEG, a dosimetrically effective distancing can be achieved.

Thus, higher irradiation doses in patients with prostate cancer can be accomplished without an increased risk of chronic side effects onto the rectal wall. Considering this successful principle of distancing, the analysis presented here verified the feasibility, tolerability, safety, and efficacy of a balloon catheter-based approach.

As a limitation, direct comparison of both approaches, with regard to acute side effects and late toxicities is difficult, since the affected OAR within the pelvis region on one hand and the abdominal cavity on the other have different tolerance doses and, moreover, the total and single doses of the irradiation concepts are not comparable.

In addition, in recent years, numerous studies have been published regarding interstitial brachytherapy of the liver $[12,13,30,31,32,33,34,35,36]$. The rate of side effects $\geq 3$ listed in these studies was approximately $5 \%$.

In contrast, the rate of late toxicities $\geq 3(12.9 \%)$ in this study appears to be higher in comparison to the cited studies. Can one or two additionally applied balloon catheter(s) cause this difference? This is rather unlikely because in the affected patients, the pre-treatment modes 
(selective internal radiotherapy, surgical procedures, chemotherapy, repeated irradiation) as well as severe co-morbidities (insulin-dependent diabetes mellitus, chronic gastritis etc.) must be taken into consideration. Moreover, the intraoperative situs of the second (gastrectomized) patient (no. 11) also showed a recurrent liver metastasis, which had infiltrated and damaged a large area of the wall of the reconstructed upper GI tract.

Thus, the iBT (plus balloon)-related complication rate summarizing all side effects $\geq 3$ (according to CTCAE v. 4.0) would be formally $3 \%$ (patient no. 20 with ulcer 4 ).

A further limitation of the study is the moderate number of cases and the retrospective and monocentric character of the analysis. In addition, the balloon catheters used are not optimal because they cannot distance the adjacent OARs in large space, only in very circumscribed areas. However, as far as known, there is currently no report on increasing the distance between tumor lesion and adjacent OAR by balloon catheter(s).

For optimization, reusable balloon catheters should be designed to be inflated and deflated when in position. In order to avoid selection bias, the results of this analysis should be examined in a prospective, possibly multicenter study.

\section{Conclusions}

Insertion of balloon catheters to increase the distance between subcapsular liver malignomas and adjacent OAR is feasible, low-risk (i.e., safe), and minimally invasive to significantly reduce the radiation dose exposure of the affected OAR due to iBT. This distancing of the adjacent OAR allows a higher $\mathrm{D}_{100}$ value of the CTV, therefore allowing for more efficient local control. Consequently, efficacy and sustainability of radio-ablative procedures can be increased.

During a short-term single-fraction iBT, an additional balloon catheter is well tolerated. Whether the insertion of such a catheter would also be possible for a longer period of several days within a fractional SBRT (several days) is currently still not investigated by a systematic study approach.

Thus, the insertion of a balloon catheter in cases with close-fitting OAR, which also overcomes the limitations of percutaneous, non-interventional SBRT, should be further discussed and more extensively proven as an additional option.

\section{Addendum}

This work has been conducted without research support.

Results of an interim analysis of this study with 20 patients were presented at the DEGRO-Congress (Hamburg) in 2015, final results at the ESTRO-Congress in Barcelona 2018.

\section{Disclosure}

Authors report no conflict of interest.

Dr. Hass reports personal fees from Merck Serono and BMS outside the submitted work.
Dr. Seidensticker reports personal fees from Bayer, grants and personal fees from SIRTEX Medical, personal fees from Cook Medical, personal fees from BTG, outside the submitted work.

\section{References}

1. Hellmann S, Weichselbaum RR. Oligometastases. J Clin Oncol 1995; 13: 8-10.

2. Hughes KS, Rosenstein RB, Songhorabodi $S$ et al. Resection of the liver for colorectal carcinoma metastases: a multi-institutional study of long-term survivors. Dis Colon Rectum 1988; 31: 1-4.

3. Pawlik TM, Scoggins CR, Zorzi D et al. Effect of surgical margin status on survival and site of recurrence after hepatic resection for colorectal metastases. Ann Surg 2005; 241: 715-722.

4. House MG, Ito H, Gönen M et al. Survival after hepatic resection for metastatic colorectal cancer: trends in outcomes for 1,600 patients during two decades at a single institution. J Am Coll Surg 2010; 210: 744-752.

5. Weichselbaum RR, Hellmann S. Oligometastases revisited. Nat Rev Clin Oncol 2011; 190: 378-382.

6. Simmonds PC, Primrose JN, Colquitt JL et al. Surgical resection of hepatic metastases from colorectal cancer: a systematic review of published studies. Br J Cancer 2006; 10: 982-999.

7. Hass P, Mohnike K. Extending the frontiers beyond thermal ablation by Radiofrequency Ablation: SBRT, Brachytherapy, SIRT. Visc Med 2014; 30: 245-252.

8. Van Cutsem E, Cervantes A, Adam R et al. ESMO consensus guidelines for the management of patients with metastatic colorectal cancer. Ann Oncol 2016; 27: 1386-1422.

9. Dawson LA. Overview: Where does radiation therapy fit in the spectrum of liver cancer local-regional therapies? Semin Radiat Oncol 2011; 21: 241-246.

10. Schefter TE, Kavanagh BD. Radiation therapy for liver metastases. Semin Radiat Oncol 2011; 21: 264-270.

11. Rusthoven KE, Kavanagh BD, Gardenes H et al. Multi-institutional phase I/II trial of stereotactic body radiation therapy for liver metastases. J Clin Oncol 2009; 27: 1572-1578.

12. Ricke J, Wust P, Stohlmann et al. CT-guided interstitial brachytherapy of liver malignancies alone or in combination with thermal ablation: Phase I-II results of a novel technique. Int J Radiat Oncol Biol Phys 2004; 58: 1496-1505.

13. Ricke J, Mohnike K, Pech M et al. Local response and impact on survival after local ablation of liver metastases from colorectal carcinoma by computed tomography-guided highdose-rate brachytherapy. Int J Radiat Oncol Biol Phys 2010; 78: 479-485.

14. Bretschneider T, Ricke J, Gebauer B et al. Image-guided highdose-rate brachytherapy of malignancies in various inner organs - technique, indications, and perspectives. J Contemp Brachytherapy 2016; 8: 251-261.

15. Streitparth F, Pech M, Bohmig M et al. In vivo assessment of the gastric mucosal tolerance dose after single fraction, small volume irradiation of liver malignancies by computed tomography-guided, high-dose-rate brachytherapy. Int $\mathrm{J} \mathrm{Ra-}$ diat Oncol Biol Phys 2006; 65: 1478-1486.

16. Wieners G, Mohnike K, Peters N et al. Treatment of hepatic metastases of breast cancer with CT-guided interstitial brachytherapy - a phase II-study. Radiother Oncol 2011; 100: 314-319.

17. Timmermann RD. An overview of hypofractionation and introduction to this issue of seminars in radiation oncology. Semin Radiat Oncol 2008; 18: 215-222.

18. Herfarth KK, Debus J, Lohr F et al. Stereotactic single-dose radiation therapy of liver tumors: results of a phase I/II trial. J Clin Oncol 2001; 19: 164-170. 
19. Sterzing F, Brunner TB, Ernst I et al. Stereotactic body radiotherapy for liver tumors. Strahlenther Onkol 2014; 190: 872881.

20. Hanley JA, McNeil BJ. The meaning and use of the area under a receiver operating characteristic (ROC) curve. Radiology 1982; 143: 29-36.

21. Bland JM, Altman DG. Statistical methods for assessing agreement between two methods of clinical measurement. Lancet 1986; 1: 307-310.

22. Misiakos EP, Karidis NP, Kouraklis G. Current treatment for colorectal liver metastases. World J Gastroenterol 2011; 17: 4067-4075.

23. Stein A, Schmoll HJ. Systemic treatment of liver metastases from colorectal cancer. Ther Adv Med Oncol. 2013; 5: 193-203.

24. Brown JM, Koong AC. High-dose single-fraction radiotherapy: exploiting a new biology? Int J Radiat Oncol Biol Phys 2008; 71: 324-325.

25. Murray D, McBride WH, Schwartz JL. Radiation biology in the context of changing patterns of radiotherapy. Radiat Res 2014; 182: 259-272.

26. Chang DT, Schellenberg D, Shen J et al. Stereotactic radiotherapy for unresectable adenocarcinoma of the pancreas. Cancer 2009; 115: 665-672.

27. Brunner TB, Nestle U, Adebahr S et al. Simultaneous integrated protection: A new concept for high-precision radiation therapy. Strahlenther Onkol 2016; 192: 886-894.

28. Song DY, Herfarth KK, Uhl M et al. A multi-institutional clinical trial of rectal dose reduction via injected polyethylene-glycol hydrogel during IMRT for prostate cancer: Analysis of dosimetric outcomes. Int J Radiat Oncol Biol Phys 2013; 87: 81-87.

29. Uhl M, van Triest B, Eble MJ et al. Low rectal toxicity after dose escalated IMRT treatment of prostate cancer using an absorbable hydrogel for increasing and maintaining space between the rectum and prostate: Results of a multi-institutional phase II trial. Radiother Oncol 2013; 106: 215-219.

30. Pinkawa M, Berneking V, König L et al. Hydrogel injection reduces rectal toxicity after radiotherapy for localized prostate cancer. Strahlenther Onkol 2017; 193: 22-28.

31. Mohnike K, Wolf S, Damm R et al. Radioablation of liver malignancies with interstitial high-dose-rate brachytherapy: Complications and risk factors. Strahlenther Onkol 2016; 192: 288-296.

32. Tselis N, Chatzikonstantinou G, Kolotas C et al. Computed-tomography-guided interstitial high dose rate brachytherapy for centrally located liver tumour: a single institution study. Eur Radiol 2013; 23: 2264-2270.

33. Mohnike K, Wieners G, Schwartz F et al. Computed tomography-guided high-dose-rate brachytherapy in hepatocellular carcinoma: Safety, efficacy and effect on survival. Int J Radiat Oncol Biol Phys 2010; 78: 172-179.

34. Bretschneider T, Mohnike K, Hass P et al. Efficacy and safety of image-guided interstitial single fraction high-dose-rate brachytherapy in the management of metastatic malignant melanoma. J Contemp Brachytherapy 2015; 2: 154-160.

35. Sharma DN, Thulkar S, Sharma S et al. High-dose-rate interstitial brachytherapy for liver metastases: first study from India. J Contemp Brachytherapy 2013; 5: 70-75.

36. Sharma DN, Thulkar S, Kumar R et al. Interstitial brachytherapy for liver metastases and assessment of response by positron emission tomography: a case report. J Contemp Brachytherapy 2010; 2: 114-116. 